\title{
CrystEngComm
}

Check for updates

Cite this: CrystEngComm, 2019, 21, 155

Received 18th September 2018, Accepted 16th November 2018

DOI: $10.1039 /$ c8ce01596a

rsc.li/crystengcomm

\section{Solubility investigations in the amorphous calcium magnesium carbonate system $\dagger$}

\author{
Bettina Purgstaller, (iD *a Katja E. Goetschl, ${ }^{a}$ \\ Vasileios Mavromatis $^{\mathrm{ab}}$ and Martin Dietzel ${ }^{\mathrm{a}}$
}

\begin{abstract}
Amorphous precursors are known to occur in the early stages of carbonate mineral formation in both biotic and abiotic environments. Although the $\mathrm{Mg}$ content of amorphous calcium magnesium carbonate (ACMC) is a crucial factor for its temporal stabilization, to date little is known about its control on ACMC solubility. Therefore, amorphous $\mathrm{Ca}_{x} \mathrm{Mg}_{1-x} \mathrm{CO}_{3} \cdot n \mathrm{H}_{2} \mathrm{O}$ solids with $0 \leq x \leq 1$ and $0.4 \leq n \leq 0.8$ were synthesized and dispersed in $\mathrm{MgCl}_{2}-\mathrm{NaHCO}_{3}$ buffered solutions at $24.5 \pm 0.5^{\circ} \mathrm{C}$. The chemical evolution of the solution and the precipitate clearly shows an instantaneous exchange of ions between ACMC and aqueous solution. The obtained ion activity product for ACMC (IAPACMC = "solubility product") increases as a function of its $\mathrm{Mg}$ content $\left([\mathrm{Mg}]_{\mathrm{ACMC}}=(1-x) \times 100\right.$ in mol\%) according to the expression: $\log \left(\mid \mathrm{AP} \mathrm{P}_{\mathrm{ACMC}}\right)=$ $0.0174( \pm 0.0013) \times[\mathrm{Mg}]_{\mathrm{ACMC}}-6.278( \pm 0.046)\left(R^{2}=0.98\right)$, where the $\log \left(\mathrm{IAP} \mathrm{ACMC}_{\mathrm{ACM}}\right)$ shift from Ca $(-6.28 \pm$ $0.05)$ to $M g(-4.54 \pm 0.16)$ ACMC endmember, can be explained by the increasing water content and changes in short-range order, as $\mathrm{Ca}$ is substituted by $\mathrm{Mg}$ in the ACMC structure. The results of this study shed light on the factors controlling ACMC solubility and its temporal stability in aqueous solutions.
\end{abstract}

\section{Introduction}

Amorphous calcium carbonate (ACC) is a highly soluble solid phase that commonly occurs as a precursor of crystalline $\mathrm{CaCO}_{3}$ (e.g. calcite, aragonite) in modern biotic and abiotic precipitation environments. Its (trans)formation has been observed in calcifying organisms, ${ }^{1-8}$ microbialites from alkaline lakes, ${ }^{9,10}$ biofilms from hot springs ${ }^{11}$ and speleothems. ${ }^{12}$ ACC can include significant amounts of $\mathrm{MgCO}_{3}$, which is known to play a significant role in its temporal stabilization. ${ }^{8,10}$ In this context, the transformation of amorphous calcium magnesium carbonates (ACMC) into crystalline $\mathrm{Ca}-\mathrm{Mg}$ carbonate minerals is of particular interest as it represents an energetically favorable pathway for high magnesian-calcite (Mg-calcite) and disordered dolomite formation. ${ }^{13-17}$ However, the impact of $\mathrm{Mg}$ on the temporal stability and transformation behavior of ACMC is not fully elucidated and a systematic study on the solubility of the ACMC system is still missing.

The earlier experimental work of Brečević and Nielsen ${ }^{18}$ showed that Mg-free ACC is significantly more soluble than

\footnotetext{
${ }^{a}$ Institute of Applied Geosciences, Graz University of Technology, Rechbauerstrasse 12, 8010 Graz, Austria. E-mail: bettina.purgstaller@tugraz.at ${ }^{b}$ Géosciences Environnement Toulouse (GET), CNRS, UMR 5563, Observatoire Midi-Pyrénées, 14 Avenue Edouard Belin, 31400 Toulouse, France

$\dagger$ Electronic supplementary information (ESI) available: Supplementary tables and thermogravimetric analyses (TGA), differential calorimetry results (DSC), X-ray diffraction patterns (XRD) and scanning electron microscope images (SEM) of synthesized ACMCs. See DOI: 10.1039/c8ce01596a
}

calcite. These authors also documented an ion activity product of ACC ( $\log \left(\mathrm{IAP}_{\mathrm{ACC}}\right)$; "solubility" of ACC) of $-6.39 \pm 0.02$ at $25{ }^{\circ} \mathrm{C}$. More recently, Gebauer et al. ${ }^{19}$ found the solubility of ACC to be lower and reported $\log \left(\mathrm{IAP}_{\mathrm{ACC}}\right)$ values of -7.51 and -7.42 for ACC phases with a "calcite-like" and a "vaterite-like" short range order, respectively. To our knowledge the only published values so far for ACMC are those obtained in our previous study (Purgstaller et al. ${ }^{15}$ ), where we documented $\log \left(\mathrm{IAP}_{\mathrm{ACMC}}\right)$ values ranging from -6.14 to -7.01 for $\mathrm{ACMC}$ with $\leq 10 \mathrm{~mol} \% \mathrm{Mg}$.

In the scope of an energetic study on synthetic ACMCs, Radha et al. ${ }^{20}$ observed that ACMC with low $\mathrm{Mg}$ content transforms faster into crystalline carbonates than ACMC with high $\mathrm{Mg}$ content under atmospheric conditions. The longer stability of ACMC with elevated Mg content has been attributed to the strong bond between structural water and $\mathrm{Mg}$ ions which retards the process of dehydration and subsequent phase transformation. ${ }^{20,21}$ However, inconsistent data are available for the water contents of ACMC at distinct $\mathrm{Mg}$ concentrations. ${ }^{20-22}$ For example, the moles of water per unit formula $\mathrm{Ca}_{x} \mathrm{Mg}_{1-x} \mathrm{CO}_{3}$ are reported to vary from 0.81 to 1.75 for ACMC with $45 \pm 2 \mathrm{~mol} \% \mathrm{Mg}^{.20,21}$

New findings indicate that the stability of Mg-free ACC under atmospheric conditions is significantly controlled by the availability of $\mathrm{H}_{2} \mathrm{O}$ in the transformation environment. In this regard, Konrad et al. ${ }^{23}$ proposed that $\mathrm{H}_{2} \mathrm{O}$ molecules are adsorbed by ACC promoting its transformation into calcite/ vaterite via a dissolution and reprecipitation mechanism. 
More recently, experimental studies on ACMC (trans)formation in an aqueous solution suggested that the chemical composition of the reactive solution (e.g. $\mathrm{Mg} / \mathrm{Ca}$ ratio) significantly affects the temporal stability of ACMC and its subsequent transformation into the final product (Mg-calcite, monohydrocalcite etc.). ${ }^{24-27}$ However, the exact mechanisms controlling ACMC stability and transformation behavior is still under debate and further experimental work is needed to describe the interaction between solutions and ACMC phases.

The aim of the present work is to provide an advanced understanding about the "solubility product" of ACMC as a function of its $\mathrm{Mg}$ content in terms of an ion activity product at chemical steady-state conditions. Therefore, distinct ACMCs $\left(\mathrm{Ca}_{x} \mathrm{Mg}_{1-x} \mathrm{CO}_{3} \cdot n \mathrm{H}_{2} \mathrm{O} ; 0 \leq x \leq 1\right.$ and $\left.0.4 \leq n \leq 0.8\right)$ were synthesized and subsequently dispersed in $\mathrm{MgCl}_{2}-$ $\mathrm{NaHCO}_{3}$ buffered solutions in order to assess i) the elemental exchange of ACMC with the aqueous phase and ii) the factors controlling ACMC solubility and its temporal stability in aqueous solutions.

\section{Experimental section}

\section{Synthesis of amorphous calcium magnesium carbonates}

Amorphous calcium magnesium carbonates with $\mathrm{Mg}$ contents ranging from 0 to $100 \mathrm{~mol} \% \mathrm{Mg}$ (hereafter referred to as ACMCs) were synthesized by a previously described method. ${ }^{23}$ Briefly, $80 \mathrm{~mL}$ of a $250 \mathrm{mM}$ (Ca, $\left.\mathrm{Mg}\right) \mathrm{Cl}_{2}$ solution was poured into a beaker containing $80 \mathrm{~mL}$ of a $250 \mathrm{mM}$ $\mathrm{Na}_{2} \mathrm{CO}_{3}$ solution. The reaction products were immediately separated from solution by a $0.2 \mu \mathrm{m}$ cellulose filter using a suction filtration unit. Subsequently, the separated precipitate was washed with ultrapure water (Millipore Integral 3: $18.2 \mathrm{M} \Omega \mathrm{cm}^{-1}$ ) and transferred into a freeze dryer (Virtis Benchtop 3L). The freeze-dried ACMCs were stored in closed vials in a desiccator with silica gel (relative humidity $=3 \%$ ). In total, 9 synthesis experiments were carried out, where the $\mathrm{Mg}$ content of the $(\mathrm{Ca}, \mathrm{Mg}) \mathrm{Cl}_{2}$ stock solution, $[\mathrm{Mg}]_{\text {stock }}=\{[\mathrm{Mg}] /([\mathrm{Ca}]+[\mathrm{Mg}])\} \times 100$, was systematically varied between 0 and $100 \mathrm{~mol} \%$ (see Table 1). All solutions were prepared by analytical grade chemicals
$\left(\mathrm{CaCl}_{2} \cdot 2 \mathrm{H}_{2} \mathrm{O}, \mathrm{MgCl}_{2} \cdot 6 \mathrm{H}_{2} \mathrm{O}\right.$ and $\mathrm{Na}_{2} \mathrm{CO}_{3}$ from Roth) mixed with ultrapure water.

\section{Experimental setup for solubility study}

The chemical composition of the synthesized ACMC solids used for solubility investigations is shown in Table 1. Experiments were performed at $24.5 \pm 0.5{ }^{\circ} \mathrm{C}$ in a $100 \mathrm{~mL}$ glass reactor containing $50 \mathrm{~mL}$ of a $100 \mathrm{mM} \mathrm{NaHCO}$ and $30 \mathrm{mM}$ $\mathrm{MgCl}_{2}$ solution, stirred at $350 \mathrm{rpm}$. The $\mathrm{pH}$ of the solution was adjusted to $8.33 \pm 0.03$ by the addition of a $500 \mathrm{mM}$ $\mathrm{NaOH}$ solution. At the onset of the experiment, $1.5 \mathrm{~g}$ of the synthetic ACMC sample was introduced into the reactor. The temporal evolution of the mineralogy was monitored using an in situ Raman probe immersed in the suspension. In order to follow the chemical composition of the solution and the solid phase, homogeneous sub-samples of the experimental solution/suspension $(1.5 \mathrm{~mL})$ were collected with a pipette at certain reaction times (Table $\mathrm{S} 1 \dagger$ ). The solids were separated from the solution by a $0.2 \mu \mathrm{m}$ cellulose acetate filter using a suction filtration unit, washed with ethanol and dried in an oven at $40^{\circ} \mathrm{C}$.

\section{Solid phase characterization}

X-ray diffraction (XRD) patterns of the synthesized ACMCs (Fig. $\mathrm{S} 1 \dagger$ ) and of the ACMCs separated from the experimental solutions during the solubility study (not shown) were acquired using a PANalytical X'Pert Pro diffractometer (Co-K $\alpha$ radiation) at a $2 \Theta$ range from 4 to $85^{\circ}$ and a scan speed of $0.03^{\circ} \mathrm{s}^{-1}$. Thermogravimetric analyses (TGA) of freeze-dried ACMCs (Fig. S2 $\dagger$ ) were realized using a PerkinElmer STA8000. The samples were heated from $25{ }^{\circ} \mathrm{C}$ to $800{ }^{\circ} \mathrm{C}$ at $10{ }^{\circ} \mathrm{C} \min ^{-1}$ in the presence of $99.999 \% \mathrm{~N}_{2}$ atmosphere. Selected synthesized ACMCs were gold coated and imaged (Fig. S3†) using a scanning electron microscope (SEM, ZEISS DSM 982 Gemini). Time-resolved in situ Raman spectroscopy of the experimental solution/suspension was realized using a Raman RXN2 ${ }^{\mathrm{TM}}$ analyzer from Kaiser Optical Systems with a Kaiser MR Probe head (quarter-inch immersion optic) and a $785 \mathrm{~nm}$ laser beam. In situ Raman spectra were collected every $60 \mathrm{~s}$ in the $100-1890 \mathrm{~cm}^{-1}$ region with a resolution of 1 $\mathrm{cm}^{-1}$.

Table 1 Chemical composition of synthesized ACMCs

\begin{tabular}{lcccc}
\hline Sample & {$[\mathrm{Mg}]_{\text {stock }}{ }^{a}(\mathrm{~mol} \%)$} & {$[\mathrm{Mg}]_{\text {ACMC }}{ }^{b}(\mathrm{~mol} \%)$} & $n \mathrm{H}_{2} \mathrm{O}_{\text {p.f. }}{ }^{c}(\mathrm{~mol})$ & Sample composition \\
\hline ACC & 0 & 0 & 0.44 & $\mathrm{CaCO}_{3} \cdot 0.44 \mathrm{H}_{2} \mathrm{O}$ \\
ACMC_9 & 20.1 & 9.0 & 0.49 & $\mathrm{Ca}_{0.91} \mathrm{Mg}_{0.09} \mathrm{CO}_{3} \cdot 0.49 \mathrm{H}_{2} \mathrm{O}$ \\
ACMC_15 & 30.3 & 14.9 & 0.51 & $\mathrm{Ca}_{0.85} \mathrm{Mg}_{0.15} \mathrm{CO}_{3} \cdot 0.51 \mathrm{H}_{2} \mathrm{O}$ \\
ACMC_22 & 40.1 & 21.9 & 0.53 & $\mathrm{Ca}_{0.78} \mathrm{Mg}_{0.22} \mathrm{CO}_{3} \cdot 0.53 \mathrm{H}_{2} \mathrm{O}$ \\
ACMC_31 & 50.1 & 30.8 & 0.56 & $\mathrm{Ca}_{0.69} \mathrm{Mg}_{0.31} \mathrm{CO}_{3} \cdot 0.56 \mathrm{H}_{2} \mathrm{O}$ \\
ACMC_39 & 60.7 & 39.4 & 0.59 & $\mathrm{Ca}_{0.61} \mathrm{Mg}_{0.39} \mathrm{CO}_{3} \cdot 0.59 \mathrm{H}_{2} \mathrm{O}$ \\
ACMC_53 & 72.1 & 53.4 & 0.66 & $\mathrm{Ca}_{0.47} \mathrm{Mg}_{0.53} \mathrm{CO}_{3} \cdot 0.66 \mathrm{H}_{2} \mathrm{O}$ \\
ACMC_80 & 89.1 & 80.0 & 0.71 & $\mathrm{Ca}_{0.20} \mathrm{Mg}_{0.80} \mathrm{CO}_{3} \cdot 0.71 \mathrm{H}_{2} \mathrm{O}$ \\
AMC & 100 & 100 & 0.79 & $\mathrm{MgCO}_{3} \cdot 0.79 \mathrm{H}_{2} \mathrm{O}$
\end{tabular}

${ }^{a} \mathrm{Mg}$ content of the stock solution in mol\%. ${ }^{b} \mathrm{Mg}$ content of the ACMC solid in mol\%. ${ }^{c}$ Moles of water per formula unit $\mathrm{Ca}_{x} \mathrm{Mg}_{1-x} \mathrm{CO}_{3}$, where $(1-x)=[\mathrm{Mg}]_{\mathrm{ACMC}} / 100$. 
Chemical composition of the experimental solutions and solids

During the experimental run, the $\mathrm{pH}$ of the experimental solution was measured with a SI Analytics Silamid® gel electrode, which was calibrated against NIST buffer standard solutions at pH 4.01 and 7.00. The total alkalinity of the experimental solutions was measured by a Schott TitroLine alpha plus titrator using a $10 \mathrm{mM} \mathrm{HCl}$ solution with a precision of $\pm 2 \%$. The aqueous $\mathrm{Ca}, \mathrm{Mg}$ and $\mathrm{Na}$ concentrations of the $(\mathrm{Ca}, \mathrm{Mg}) \mathrm{Cl}_{2}$ stock solutions, of the experimental solutions and of the solids (digested in $6 \% \mathrm{HNO}_{3}$ ) were determined using inductively coupled plasma optical emission spectrometry (Perkin Elmer Optima 8300 DV). The analytical error was $< \pm 3 \%$ for $\mathrm{Ca}$ and $\mathrm{Mg}$ analyses and $< \pm 5 \%$ for $\mathrm{Na}$ analyses.

\section{Aqueous speciation and ion activity product calculation}

The aqueous speciation of the experimental solutions was calculated at $25{ }^{\circ} \mathrm{C}$ using the PHREEQC software together with its minteq.v4 database. For the ionic strength of our experiments (i.e. $0.17 \pm 0.02 \mathrm{M}$; Table $\mathrm{S} 2 \dagger$ ), the calculation of individual ion activity coefficients for the solute species is based on the Davis equation. ${ }^{28,29}$ The activities $(a)$ of $\mathrm{Ca}^{2+}$, $\mathrm{Mg}^{2+}$ and $\mathrm{CO}_{3}{ }^{2-}$ ions in solution and the stoichiometry of the digested $\mathrm{Ca}_{x} \mathrm{Mg}_{1_{-x}} \mathrm{CO}_{3} \cdot n \mathrm{H}_{2} \mathrm{O}$ solids (where $(1-x)=[\mathrm{Mg}]_{\text {ACMC }} /$ 100) were used to calculate ion activity products for the amorphous calcium magnesium carbonates $\left(\mathrm{IAP}_{\mathrm{ACMC}}\right)$ as a function of experimental time according to equation

$$
\operatorname{IAP}_{\mathrm{ACMC}}=\left(a \mathrm{Ca}^{2+}\right)^{x}\left(a \mathrm{Mg}^{2+}\right)^{1-x}\left(a \mathrm{CO}_{3}{ }^{2-}\right)\left(a \mathrm{H}_{2} \mathrm{O}\right)^{n}
$$

In the present solubility experiments, the $a \mathrm{H}_{2} \mathrm{O}$ values of the experimental solutions remained constant at $0.955 \pm$ 0.004. Thus, for the calculation of the $\mathrm{IAP}_{\mathrm{ACMC}}$, the $a \mathrm{H}_{2} \mathrm{O}$ was assumed to be unity.

\section{Results and discussion}

\section{Characterization of synthesized ACMC material}

The measured $\mathrm{Mg}$ contents of the stock solutions, $[\mathrm{Mg}]_{\text {stock }}$, and of the synthesized ACMC samples, $[\mathrm{Mg}]_{\mathrm{ACMC}}$, are reported in Table 1 and displayed in Fig. 1. The results reveal a preferential enrichment of the amorphous solid in $\mathrm{Ca}$ and are in good agreement with those of Radha et al. ${ }^{20}$ who synthesized a set of amorphous $\mathrm{Ca}_{x} \mathrm{Mg}_{1-x} \mathrm{CO}_{3} \cdot n \mathrm{H}_{2} \mathrm{O}$ solids by batch method using (Ca, Mg) $\mathrm{Cl}_{2}$ and $\mathrm{Na}_{2} \mathrm{CO}_{3}$ solutions (Fig. 1). The preferential enrichment of the amorphous phase in Ca likely stems from the strong free energy of hydration of the $\mathrm{Mg}^{2+}$ ion compared to $\mathrm{Ca}^{2+} \cdot{ }^{20,30}$ The strongly hydrated aqueous $\mathrm{Mg}^{2+}$ is a well-known limitation in the formation of anhydrous crystalline $\mathrm{Ca}-\mathrm{Mg}$-carbonates, such as $\mathrm{Mg}$-calcite, dolomite and magnesite, at ambient temperatures. ${ }^{31}$ Instead, hydrous crystalline Mg-carbonates (e.g. hydromagnesite) ${ }^{32}$ and hydrous ACMC phases ${ }^{33,34}$ tend to precipitate.

Representative thermogravimetric analysis (TGA) and differential scanning calorimetry (DSC) curves of the synthe-

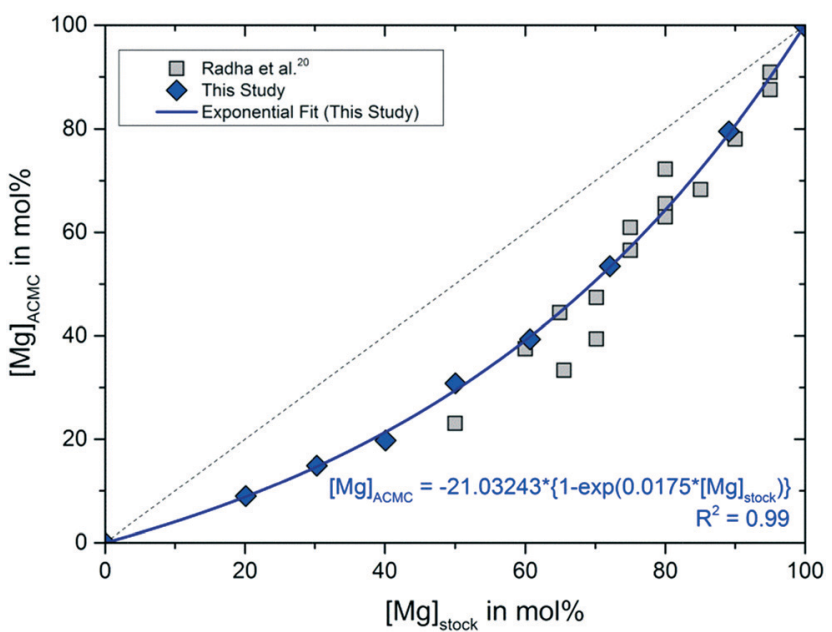

Fig. $1 \mathrm{Mg}$ content of the stock colutions, $[\mathrm{Mg}]_{\text {stock, versus } \mathrm{Mg}}$ content of the $A C M C$ precipitates, $[\mathrm{Mg}]_{\mathrm{ACMC}}$, and respective values reported by Radha et al. ${ }^{20}$ The increase of $[\mathrm{Mg}]_{\mathrm{ACMC}}$ as a function of $[\mathrm{Mg}]_{\text {stock }}$ of this study can be described by the equation $[\mathrm{Mg}]_{\mathrm{ACMC}}=$ $-21.03243 \pm 2.1968 \times\left\{1-\exp \left(0.0175 \pm 0.0009 \times[M g]_{\text {stock }}\right)\right\}\left(R^{2}=\right.$ 0.99 ; solid line). Analytical uncertainties are included in the symbol size.

sized ACMCs are presented in Fig. S2 (ESI $\dagger$ ). The DSC curve of ACC (Ca endmember of ACMC) shows an endothermic peak at $120{ }^{\circ} \mathrm{C}$, a sharp exothermic peak at $340{ }^{\circ} \mathrm{C}$ and a second endothermic peak at $731^{\circ} \mathrm{C}$ (Fig. S2A $\dagger$ ). These DSC features have been earlier shown to be associated with the enthalpies of dehydration, crystallization and decomposition of ACC. ${ }^{20,35}$ In contrast to ACC, AMC ( $\mathrm{Mg}$ endmember of ACMC) decomposes without crystallization, as it is indicated by the absence of the sharp exothermic peak in the DSC curve (Fig. S2F $\dagger$ ). The weight loss curves of ACC and AMC show two weight loss steps (Fig. S2A and $F \dagger$ ), where the first step is due to the loss of structural water and the second step due to the decomposition of $\mathrm{CaCO}_{3}$ and $\mathrm{MgCO}_{3}$ to $\mathrm{CaO}$, $\mathrm{MgO}$ and $\mathrm{CO}_{2} \cdot{ }^{20,35}$ After ACC dehydration, the TGA curve achieves a plateau in heating before $\mathrm{CaCO}_{3}$ decomposes to $\mathrm{CaO}$ and $\mathrm{CO}_{2}$ at near $600{ }^{\circ} \mathrm{C}$ (Fig. S2A $\dagger$ ). In contrast, AMC shows a continuous drop of the TGA curve (without a plateau) for the same temperature range, which indicates that AMC dehydration and decomposition may overlap (Fig. $\mathrm{S} 2 \mathrm{~F} \dagger$ ). Based on our TGA data we suggest that AMC decomposition occurs at around $275{ }^{\circ} \mathrm{C}$, as it is indicated by the inflection point of the weight loss curve (Fig. S2F $\dagger$ ). In contrast to the pure endmembers, the ACMCs show multistep weight loss curves (Fig. S2B-E $\dagger$ ). These trends are in accordance with the findings of Radha et al. ${ }^{20}$ who associated these features with multistep carbonate decomposition caused by (i) an initial heterogeneous amorphous material or (ii) thermally induced phase segregation during the heating process.

The water contents of the synthetic ACMCs were calculated from the weight losses between 25 and $275^{\circ} \mathrm{C}$. Above this temperature, mass loss might occur due to the decomposition of $\mathrm{MgCO}_{3}$ to $\mathrm{MgO}$, as it is suggested by the TGA curve 


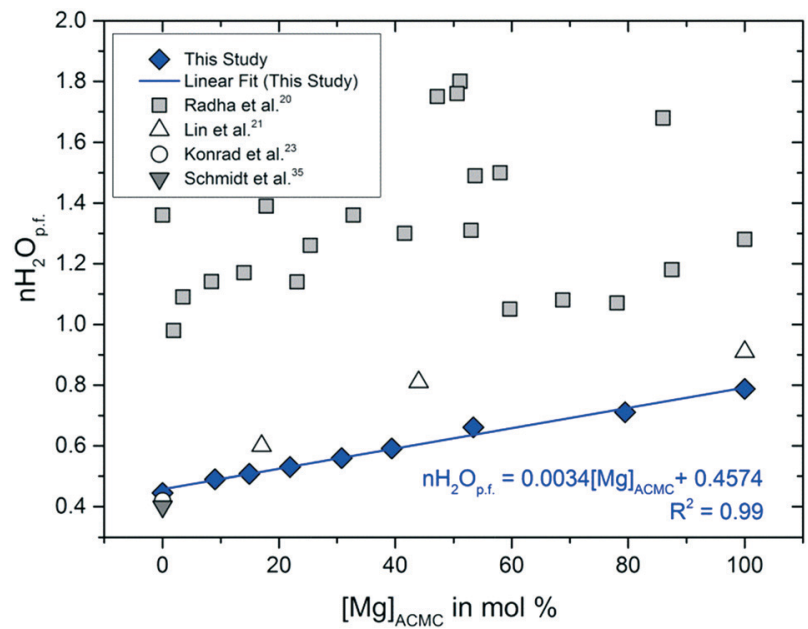

Fig. $2 \mathrm{Mg}$ content of $\mathrm{ACMC},[\mathrm{Mg}]_{\mathrm{ACMC}}$, versus the moles of water per unit formula $\mathrm{Ca}_{x} \mathrm{Mg}_{1-x} \mathrm{CO}_{3}, n \mathrm{H}_{2} \mathrm{O}_{\text {p.f., }}$ from synthesis experiments conducted in the present study and from literature. Analytical uncertainties are included in the symbol size.

of AMC (Fig. S2F $\dagger$ ). The moles of water per unit formula $\mathrm{Ca}_{x} \mathrm{Mg}_{1-x} \mathrm{CO}_{3}\left(n \mathrm{H}_{2} \mathrm{O}_{\text {p.f. }}\right)$ determined by thermal analyses vary between 0.4 for ACC and 0.8 for AMC (Table 1, Fig. 2). As it can be seen in Fig. 2, the water content determined for ACC is in excellent agreement with those reported by Schmidt et $a .^{35}$ and Konrad et al. ${ }^{23}$ Overall, thermal analyses revealed a linear correlation between the $n \mathrm{H}_{2} \mathrm{O}_{\text {p.f. }}$ and the $[\mathrm{Mg}]_{\mathrm{ACMC}}$ according to the equation

$$
n \mathrm{H}_{2} \mathrm{O}_{\text {p.f. }}=0.0034 \pm 0.0002[\mathrm{Mg}]_{\mathrm{ACMC}}+0.4574 \pm 0.0124
$$

where $R^{2}=0.99$. Previous experimental work documented sig-

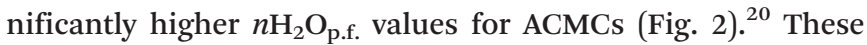
differences probably originate from different drying methods (freeze-dryer versus vacuum oven). In the study of Radha et al. ${ }^{20}$ the loosely bound physisorbed $\mathrm{H}_{2} \mathrm{O}$ on the ACMC particles were probably not completely removed by the vacuum oven prior to thermogravimetric analyses. However, our findings are in good agreement with the results of Lin

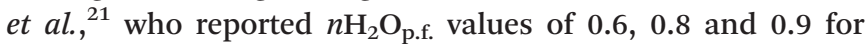
ACMC with 17, 44 and $100 \mathrm{~mol} \% \mathrm{Mg}$ (Fig. 2). In the latter case, the synthesized ACMC samples were washed with ethanol and lyophilized prior to TGA-analysis.

Earlier models on the structure of Mg-free ACC suggested the presence of partially mobile water in the amorphous phase. ${ }^{36,37}$ In this context, ACC has been described to consist of a porous Ca-framework with interconnected channels formed by water molecules and carbonate ions, allowing water mobility to a certain extent. ${ }^{38}$ More recently, Jensen et $a .^{39}$ has shown that water molecules are mainly coordinated to $\mathrm{Ca}$ and carbonate ions and less frequently to other water molecules, ruling out the scenario of hydrogen-bonded networks. This is consistent with the NMR-results of Lin et $a l^{21}$ who concluded that the coordination shell of $\mathrm{Mg}$ in ACMC contains at least one water molecule. Indeed, in the present study,

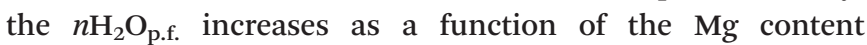
(Fig. 2), indicating that partially hydrated $\mathrm{Mg}$ is incorporated into the amorphous solid. Our obtained results how-

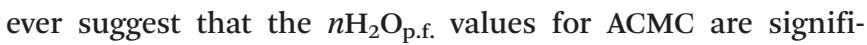
cantly lower than previously reported. ${ }^{20,22}$
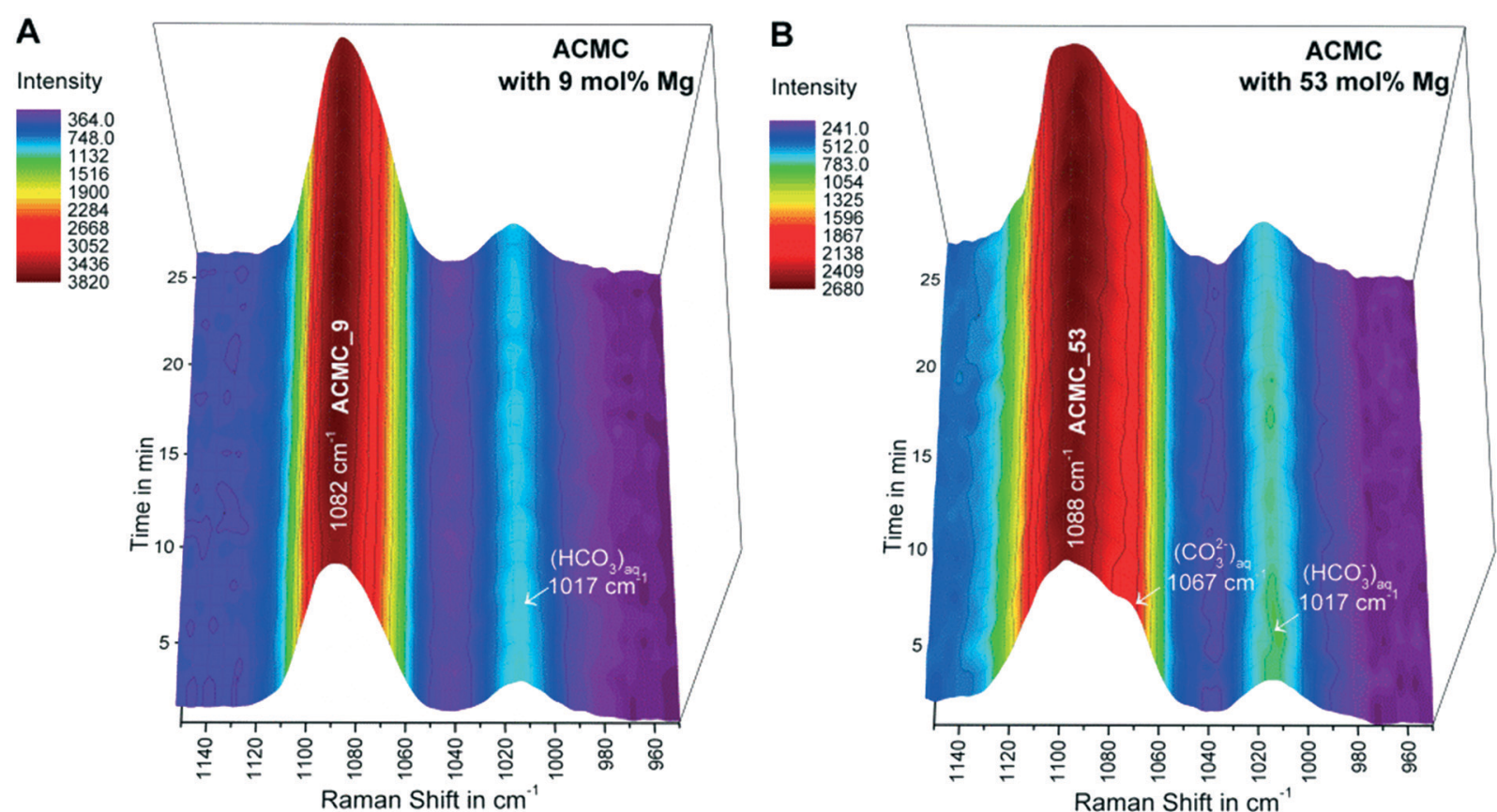

Fig. 3 3D plots of in situ Raman spectra showing the temporal evolution of the $v_{1}$ band of ACMC for the experiments conducted with ACMC_9 (A) and ACMC_53 (B). The Raman bands at $1067 \mathrm{~cm}^{-1}$ and $1017 \mathrm{~cm}^{-1}$ correspond to aqueous $\mathrm{CO}_{3}{ }^{2-}$ and $\mathrm{HCO}_{3}^{-}$, respectively. 
Table 2 Summary of in situ Raman results and calculated ion activity product values of solubility experiments

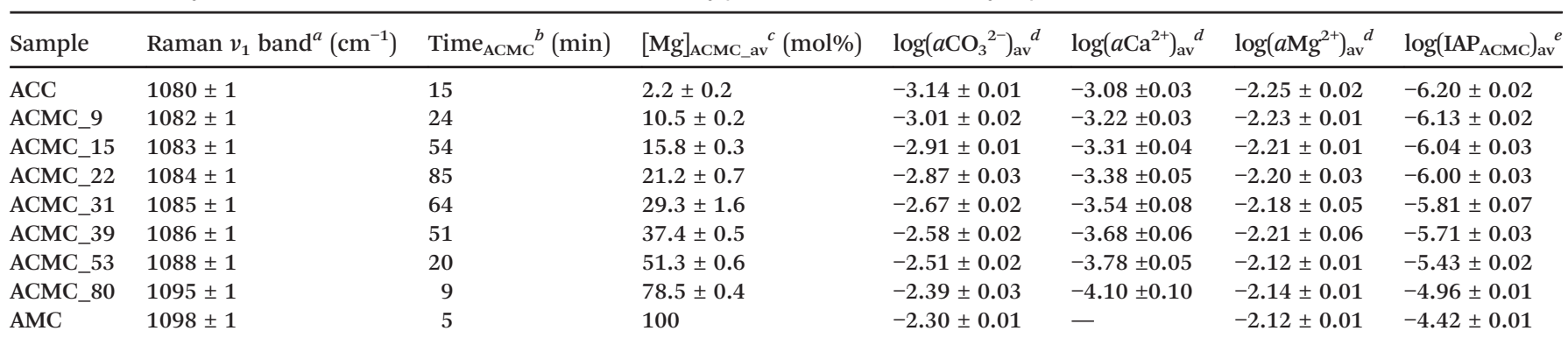

${ }^{a}$ Raman $v_{1}$ peak positions of ACMC solids dispersed in the $\mathrm{MgCl}_{2}-\mathrm{NaHCO}_{3}$ buffered solutions. ${ }^{b}$ Time interval in which ACMC was stable in the experimental solution. ${ }^{c}$ Average $\mathrm{Mg}$ content of the ACMC solid at chemical steady state conditions (used for IAP ${ }_{\mathrm{ACMC}}$ calculation). ${ }^{d}$ Average activities of $\mathrm{CO}_{3}{ }^{2-}, \mathrm{Ca}^{2+}$ and $\mathrm{Mg}^{2+}$ ions in the experimental solution at chemical steady state conditions (used for IAP ${ }_{\mathrm{ACMC}}$ calculation). ${ }^{e}$ Average ion activity product for ACMC calculated according to eqn (1). Note that the input data for speciation calculations and selected output data are listed in Table S2.

\section{Exchange of ions between ACMC and aqueous solution}

After the synthesized ACMCs were dispersed in the $\mathrm{MgCl}_{2}-$ $\mathrm{NaHCO}_{3}$ buffered solutions, the collected in situ Raman spectra of the suspensions revealed the presence of a broad $\mathrm{CO}_{3}{ }^{2-}$ symmetric stretch ( $v_{1}$ band) of ACMC at 1080-1098 $\mathrm{cm}^{-1}$ (e.g. experiments ACMC_9 and ACMC_53 in Fig. 3). The $v_{1}$ band shows systematic shifts in peak position (Table 2) and peak broadening due to different $\mathrm{Mg}$ contents of the ACMCs. These features arise from changes in the metal-oxygen bond length due to the presence of shorter $\mathrm{Mg}-\mathrm{O}$ bonds compared to those of $\mathrm{Ca}-\mathrm{O}$ in the amorphous solid. ${ }^{15,40}$ The intensities of the $v_{1}$ bands of the ACMC phases remained constant for experimental times ranging from 5 to $85 \mathrm{~min}$ (referred to as Time $_{\text {ACMC }}$ in Table 2). After this time interval, the $v_{1}$ bands of the ACMCs decreased in intensity, while the $v_{1}$ bands of crystalline hydrous and/or anhydrous $\mathrm{Ca}-\mathrm{Mg}$ carbonates (Mg-calcite, monohydrocalcite and/or nesquehonite) evolved (not shown here). Thus, Time $_{\mathrm{ACMC}}$ denotes the time interval in which the ACMC was stable in the experimental solution (Table 2). Note that, the in situ Raman observations were confirmed by ex situ XRD analyses of the collected solid samples.

Although, Time $_{\mathrm{ACMC}}$ increased as a function of the $\mathrm{Mg}$ content in experiments conducted with ACMCs containing $\leq 22 \mathrm{~mol} \% \mathrm{Mg}$, a reverse trend was obtained in experiments with ACMCs containing $>22$ mol\% (Table 2). These observations imply that the temporal stability of ACMC in a solution is not strictly controlled by its primary $\mathrm{Mg}$ content. In contrast, the obtained data revealed changes in the chemical composition of the reacting ACMC and the experimental solution which might play a crucial role in the temporal stabilization of the precursor phase and its subsequent transformation into distinct crystalline calcium magnesium carbonates.

The chemical composition of the experimental solutions and solids collected during Time ACMC can be found in Table S1.† Exemplarily, the temporal evolution of the chemical composition of the solutions and solids in experiments conducted with ACMC_53 (53 mol\% $\mathrm{Mg}$ ) and with ACMC_9 ( $9 \mathrm{~mol} \% \mathrm{Mg}$ ) is illustrated in Fig. 4A-C. The obtained results documented a significant change in the chemical composition of the solids and experimental solutions within about 10 $\mathrm{s}$ after the ACMCs were dispersed into the $\mathrm{MgCl}_{2}-\mathrm{NaHCO}_{3}$ solutions. In each experiment, chemical steady state conditions were attained at a reaction time of about 2 min (Fig. 4A-C; Table $\mathrm{S} 1 \dagger)$. The fast reaction between the amorphous solid and the solution can be explained by the nano-porous structured ACMC material consisting of large and highly reactive surface areas (Fig. $\mathrm{S} 3 \dagger$ ). The shifts in $\mathrm{pH}$ and alkalinity of the $\mathrm{MgCl}_{2}-\mathrm{NaHCO}_{3}$ buffered solution increase with increasing $\mathrm{Mg}$ content of the synthesized ACMCs (Fig. 4D). For example, dispersion of ACMC with 9 mol\% $\mathrm{Mg}$ (ACMC_9) yields a slight shift in $\mathrm{pH}$ and alkalinity from 8.3 to 8.5 and 104 to $107 \mathrm{mM}$, respectively, whereas for ACMC with $53 \mathrm{~mol} \% \mathrm{Mg}$ (ACMC_53) a significant shift in $\mathrm{pH}$ to 9.1 and alkalinity to $143 \mathrm{mM}$ was observed (Fig. 4A and B). This indicates that for attainment of chemical equilibrium between solid and solution, larger amounts of ACMC are required to dissolve in the experiment with ACMC_53 (53 mol\% $\mathrm{Mg}$ ) compared to the experiment conducted with ACMC_9 (9 mol\% $\mathrm{Mg}$ ).

The results revealed two distinctive trends of $\mathrm{Mg}$ and $\mathrm{Ca}$ exchange between ACMCs and the solution, depending on the $\mathrm{Mg}$ concentrations of synthesized ACMCs: (i) in experiments conducted with ACMCs containing $\leq 15 \mathrm{~mol} \% \mathrm{Mg}$ a net release of $\mathrm{Ca}$ into the solution together with an uptake of $\mathrm{Mg}$ from the solution into the solid is observed, which results in ACMCs with slightly higher $\mathrm{Mg}$ contents compared to the synthesized ACMC (e.g. ACMC_9 in Fig. 4B and C; Table S1†). (ii) In contrast, in experiments conducted with ACMCs containing $\geq 20 \mathrm{~mol} \% \mathrm{Mg}$ a net release of $\mathrm{Mg}$ into the experimental solution and lower $[\mathrm{Mg}]_{\mathrm{ACMC}}$ values compared to the synthesized ACMCs were observed (e.g. ACMC_53 in Fig. 4B and C; Table S1†). These observations suggest a dynamic exchange of $\mathrm{Me}^{2+}\left(\mathrm{Ca}^{2+}\right.$ and $\left.\mathrm{Mg}^{2+}\right)$ ions between the amorphous solid and the experimental solution. It is likely that the total availability of $\mathrm{Me}^{2+}\left(\mathrm{Ca}^{2+}\right.$ and $\left.\mathrm{Mg}^{2+}\right)$ and $\mathrm{CO}_{3}{ }^{2-}$ ions in the prevailing solution affects the formation of distinct crystalline calcium magnesium carbonates and the temporal stability of the ACMC precursor in solution. Evidence for that also comes from a recent study on ACC transformation, 

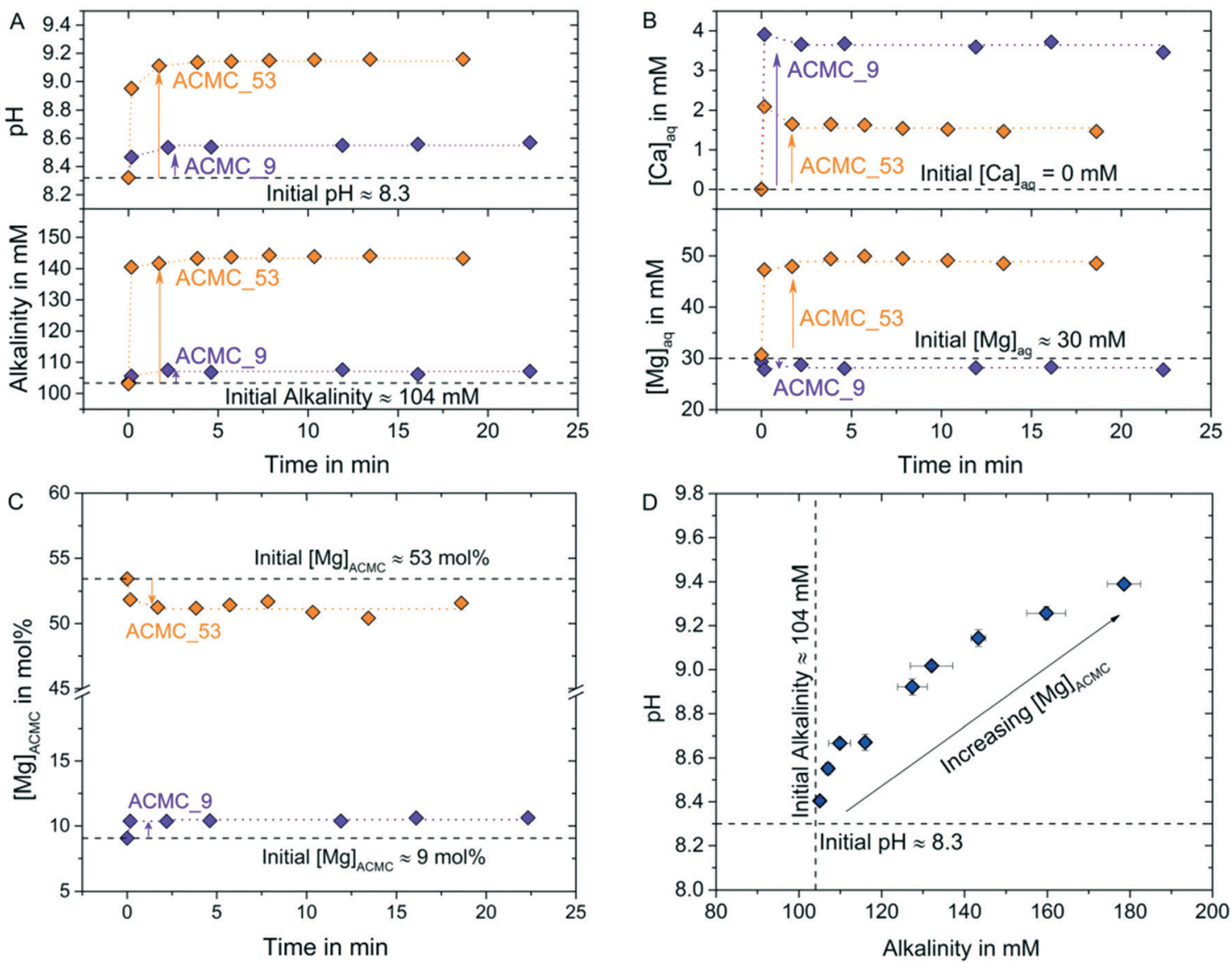

Fig. 4 Temporal evolution of (A) $\mathrm{pH}$ and alkalinity concentration, (B) aqueous $\mathrm{Ca}$ and $\mathrm{Mg}$ concentration of the experimental solution, [Ca] $]_{\mathrm{aq}}$ and $[\mathrm{Mg}]_{\mathrm{aq}}$, and (C) $\mathrm{Mg}$ content of $\mathrm{ACMC}$ solid, $[\mathrm{Mg}]_{\mathrm{ACMC}}$, after synthesized ACMC solids were dispersed into the $\mathrm{MgCl}_{2}-\mathrm{NaHCO}_{3}$ solutions. Exemplarily the data for ACMC_53 and ACMC_9 are shown, where the experimental solution achieves constant chemical composition after 2 min of reaction time. Note that chemical data obtained at $>2$ min were used for estimating the ion activity products of the distinct ACMCs according to eqn (1) (Table 2). (D) Average alkalinity concentration versus $\mathrm{pH}$ values of the experimental solution at chemical steady state conditions ( $>2$ min, see Table $\mathrm{S} 2 \uparrow)$. The shifts in $\mathrm{pH}$ and alkalinity increase with increasing $[\mathrm{Mg}]_{\mathrm{ACMC}}$.

showing prolonged stability of Mg-free ACC of up to $~ 11$ hours in high concentrated $\mathrm{MgCl}_{2}$ solutions (up to $1000 \mathrm{mM}$ ). ${ }^{26}$ It was concluded that strong aquocomplex formation of the dissolved carbonate molecule with $\mathrm{Mg}^{2+}$ ions retarded mineral formation and increased the stability of ACC in solution. ${ }^{26}$

\section{Solubility approach}

The experimental solution in all experimental runs achieved chemical steady state conditions after 2 min of reaction time. These conditions remained steady during the time interval in which solid analyses (Raman spectra and XRD pattern) documented the stability of ACMC in the aqueous phase (Time $_{\mathrm{ACMC}}$ in Table 2). Thus, speciation calculations were performed at reaction times $\geq 2 \mathrm{~min}$ and $\leq$ Time $_{\mathrm{ACMC}}$. The input data for speciation calculations using PHREEQC modeling and selected output data are summarized in Table S2. $\dagger$ The results showed that the experimental solutions exhibit internal partial pressures of $\mathrm{CO}_{2}$ ranging from $10^{-1.8}$ to $10^{-2.9}$ atmospheres (see $p_{\mathrm{CO}_{2}(\mathrm{~g})}$ in Table $\mathrm{S} 2 \dagger$ ). As such, the $p_{\mathrm{CO}_{2}}$ pressure of the experimental solutions is higher compared to the atmosphere and thus $\mathrm{CO}_{2}$ is likely degassing from the experimental solutions. However, in context of the present study, samples of the suspensions were collected during a short time interval $(<45 \mathrm{~min})$ in which $p_{\mathrm{CO}_{2}(\mathrm{~g})}, \mathrm{pH}$ and alkalinity values were monitored to be constant within the analytical precision (Table S2†). Thus, the obtained activities of $\mathrm{Ca}^{2+}$, $\mathrm{Mg}^{2+}$ and $\mathrm{CO}_{3}{ }^{2-}$ ions of the solution and the ACMC stoichiometry at the given reaction time were used to calculate individual IAP $_{\text {ACMC }}$ (solubility) values according to eqn (1) (Table $\mathrm{S} 2 \dagger)$. The average $\log \left(\mathrm{IAP}_{\mathrm{ACMC}}\right)$ values are listed in Table 2 and plotted in Fig. 5 as a function of the $\mathrm{Mg}$ content of the ACMC. Note here that the average $\mathrm{Mg}$ content of the ACMC solid at chemical steady state conditions (after $\mathrm{Ca}$ and $\mathrm{Mg}$ ion exchange) was used for $\operatorname{IAP}_{\mathrm{ACMC}}$ calculations (Table 2) and was plotted in Fig. 5. The results clearly show that the solubility of ACMC increases as a function of the $\mathrm{Mg}$ content (Fig. 5). The linear fit of the $\log \left(\operatorname{IAP}_{\mathrm{ACMC}}\right)$ values obtained in the context of the present study is in good agreement with the $\log$ (IAP) value for ACC documented by Brečević and Nielsen, ${ }^{18}$ while the solubility products for ACCs reported by Gebauer et al. $^{19}$ are significantly smaller. The obtained 


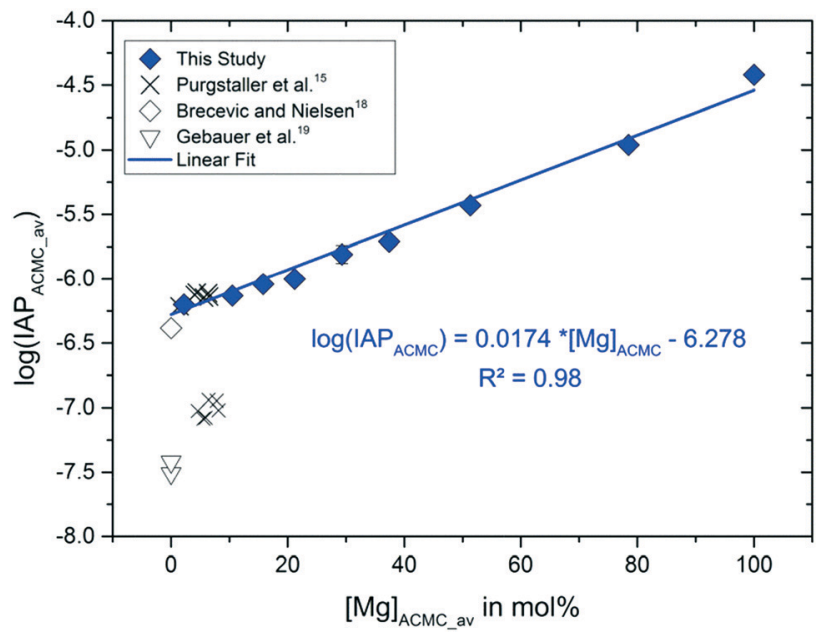

Fig. 5 Average $\mathrm{Mg}$ content of $\mathrm{ACMC},[\mathrm{Mg}]_{\mathrm{ACMC} \_a v}$, versus the average ion activity product of $A C M C, \log \left(\mathrm{IAP}_{\mathrm{ACMC}}\right)_{\mathrm{av}}$ (resembling the solubility product of the ACMC phase), calculated according to eqn (1) at chemical steady state conditions (see values in Table 2). The $\log \left({ } \mathrm{AP}_{\mathrm{ACMC}}\right)$ values for $\mathrm{Mg}$-free $\mathrm{ACC}$ are taken from Brečević and Niel$\operatorname{sen}^{18}$ and Gebauer et al., ${ }^{19}$ while those for ACMC with $\leq 10 \mathrm{~mol} \% \mathrm{Mg}$ are taken from Purgstaller et al. ${ }^{15}$ The analytical uncertainties are included in the symbol size.

$\log \left(\mathrm{IAP}_{\mathrm{ACMC}}\right)$ values of $-6.19 \pm 0.02$ and $-6.13 \pm 0.02$ for ACMCs with 2 and $10 \mathrm{~mol} \% \mathrm{Mg}$, respectively, lay within the range of $-6.14 \pm 0.04$ for the low-Mg ACMC reported by Purgstaller et $a{ }^{15}{ }^{15}$ In this respect, it has to be noted that the solids collected in the present experiments were filtered through $0.2 \mu \mathrm{m}$ membranes. Although the separation yields aggregated spherical nano-particles (see Fig. $\mathrm{S} 4 \dagger$ ) and the solutions were visibly clear after filtration, the presence of ACMC individuals in the filtered solutions cannot be completely ruled out at this stage. Partially remaining ACMC in the solution would slightly increase the measured ion concentrations. However, the linear fit of the herein obtained $\log \left(\mathrm{IAP}_{\mathrm{ACMC}}\right)$ values is in good agreement with the $\log \left(\mathrm{IAP}_{\mathrm{ACC}}\right)$ value from Brečević and Nielsen, ${ }^{18}$ who determined the solubility of ACC by titration of water into the suspension without physical separation of the solid phase, indicating the effect of ACMC individuals in the filtered solutions to be negligibly small. The positive correlation between the $\log \left(\mathrm{IAP}_{\mathrm{ACMC}}\right)$ and $[\mathrm{Mg}]_{\mathrm{ACMC}}$ values obtained from this study, from Brečević and Nielsen ${ }^{18}$ and Purgstaller et $a .^{15}$ can be described by the expression:

$$
\log \left(\mathrm{IAP}_{\mathrm{ACMC}}\right)=0.0174 \pm 0.0013 \times[\mathrm{Mg}]_{\mathrm{ACMC}}-6.278 \pm 0.046(3)
$$

where $R^{2}=0.98$.

Note here that the calculation of the $\operatorname{IAP}_{\mathrm{ACMC}}$ values is based on the assumption that the ACMCs are amorphous $\mathrm{Ca}-\mathrm{Mg}$ carbonate solid-solutions. However, a previous study on synthetic ACMCs by Radha et al. ${ }^{20}$ points towards a phase separation of ACMC solids with $\geq 47 \mathrm{~mol} \% \mathrm{Mg}$. It has been suggested that ACMC with $\geq 47 \mathrm{~mol} \%$ are composed by a mixture of a material nearly pure AMC with a material nearly $50 \mathrm{~mol} \% \mathrm{Mg}$. However, such heterogeneity may also be in- duced during the heating of the ACMC solids during thermogravimetric analyses (thermally driven $\mathrm{MgCO}_{3}$ segregation). ${ }^{20}$ More recently, the ${ }^{13} \mathrm{C}-\mathrm{NMR}$ measurements on ACMCs by Yang et al. ${ }^{41}$ showed two types of carbonate ions in synthetic ACMC solids, whose short-range orders are identical to those of ACC and AMC. Based on these observations, Yang et $a .^{41}$ suggested that the ACMC solids comprise a homogeneous mixture of the nano-clusters of ACC and AMC. In order to test the validity of the $\mathrm{Ca}-\mathrm{Mg}$ carbonate solidsolution system, we calculated the IAP values of the experimental solutions at chemical steady state conditions with respect to the endmembers ACC and AMC according to the equations $\operatorname{IAP}_{\mathrm{ACC}}=\left(a \mathrm{Ca}^{2+}\right) \cdot\left(\mathrm{aCO}_{3}{ }^{2-}\right)$ and $\operatorname{IAP}_{\mathrm{AMC}}=\left(a \mathrm{Mg}^{2+}\right)$ $\cdot\left(a \mathrm{CO}_{3}{ }^{2-}\right)$, respectively. As the $\mathrm{Mg}$ content of the solid increases from 2 to $78 \mathrm{~mol} \% \mathrm{Mg}$, the $\log \left(\mathrm{IAP}_{\mathrm{AMC}}\right)$ and $\log \left(\mathrm{IAP}_{\mathrm{ACC}}\right)$ values change from -5.4 to -4.5 and -6.2 to -6.5 , respectively. If the ACMCs consist of an ideal two phase mixture of ACC and AMC, we would expect constant $\log \left(\mathrm{IAP}_{\mathrm{ACC}}\right)$ and $\log \left(\mathrm{IAP}_{\mathrm{AMC}}\right)$ in all experiments, irrespective of the $\mathrm{Mg}$ content of the solid initially introduced into the reactor. As such, the presence of discrete AMC and ACC phases in the ACMC solid can be excluded. In contrast, the obtained linear correlation between the average $\log \left(\mathrm{IAP}_{\mathrm{ACMC}}\right)$ and $[\mathrm{Mg}]_{\mathrm{ACMC}}$ values (see Fig. 5) points toward the presence of an homogeneous single phase in each experimental run.

It is also worth pointing out that the ${ }^{13} \mathrm{C}-\mathrm{NMR}$ measurements on ACMCs by Yang et al. ${ }^{41}$ indicated the existence of bicarbonate species embedded in the matrix formed by ACC and AMC. Moreover, based on the $\mathrm{Mg}$ isotope composition of Mg-ACCs, Mavromatis et al. ${ }^{42}$ suggested that during the very fast precipitation of the amorphous phase from a highly supersaturated solution, $\mathrm{MgHCO}_{3}{ }^{+}$and $\mathrm{MgCO}_{3}{ }^{0}$ species might be directly incorporated into the precipitating solid together with $\mathrm{Mg}\left(\mathrm{H}_{2} \mathrm{O}\right)_{6}{ }^{2+}$. If this holds true, the activities of $\mathrm{Ca}$ and $\mathrm{Mg}$ carbonate species have to be considered in the calculation of the $\mathrm{IAP}_{\mathrm{ACMC}}$ values. For this purpose, however, a more detailed characterization of the structure of ACMC is required, which should be in the focus of future studies.

Although the solubility of ACC is about two orders of magnitude higher than that of calcite, the dependence of $\mathrm{IAP}_{\mathrm{ACMC}}$ on the $\mathrm{Mg}$ content of the solid (Fig. 5) is somehow similar to that observed for the Mg-calcite system. ${ }^{43}$ Indeed experimental work conducted during the last 3 decades documents an overall increase in solubility of $\mathrm{Mg}$-bearing calcites with increasing $\mathrm{Mg}$ content. ${ }^{43-45}$ Note, that significant discrepancies exist between reported solubility values of Mg-calcites, which were attributed to differences in mineral source and structure (biogenic or synthetic solids) as well as different experimental setups. ${ }^{43-45}$ The change in calcite solubility as $\mathrm{Mg}$ is incorporated in its structure can likely be attributed to the distortion of the octahedral site in calcite. The substitution of $\mathrm{Ca}$ by $\mathrm{Mg}$ in the calcite structure results in a decrease of interatomic metal-O distances and shortening of the $c$-axis. ${ }^{46,47}$ Consequently, $\mathrm{Ca}, \mathrm{C}$ and $\mathrm{O}$ atoms exhibit large thermal motions which cause periodic stretching and weakening of the bonds in the structure. ${ }^{46}$ 
In contrast to the crystalline $\mathrm{Ca}-\mathrm{Mg}$ carbonate system, amorphous carbonates exhibit no order beyond $1.5 \mathrm{~nm} .{ }^{40,48}$ In situ Raman results from the present work and from previous studies ${ }^{15,40}$ however showed that the substitution of $\mathrm{Ca}^{2+}$ by $\mathrm{Mg}^{2+}$ changes the average metal-oxygen bond lengths in the amorphous phase, which might change its short-range order and solubility. Moreover, the linear relationship between the $\mathrm{IAP}_{\mathrm{ACMC}}$ and $[\mathrm{Mg}]_{\mathrm{ACMC}}$ values (Fig. 1) as well as of the $[\mathrm{Mg}]_{\mathrm{ACMC}}$

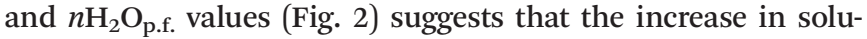
bility of ACMC as a function of the $\mathrm{Mg}$ content is attributed to the increasing water content in the structure of ACMC. A similar behavior has been observed for the hydrated crystalline $\mathrm{Mg}$ carbonate system, where the more hydrated lansfordite $\left(\mathrm{MgCO}_{3} \cdot 5 \mathrm{H}_{2} \mathrm{O}\right)$ exhibits a higher solubility than the less hydrated nesquehonite $\left(\mathrm{MgCO}_{3} \cdot 3 \mathrm{H}_{2} \mathrm{O}\right)$ at $25{ }^{\circ} \mathrm{C}$. ${ }^{49}$

\section{Conclusions}

The experimental results indicated a fast exchange of ions between the synthesized amorphous ACMC solids and the aqueous solutions, which is likely stimulated by the large surface area of the nano-porous ACMC solid. Chemical steady state conditions between ACMC and corresponding solution were reached within $2 \mathrm{~min}$ of reaction time. The calculated ion activity products documented that the solubility of ACMC increases as a function of the $\mathrm{Mg}$ content. This feature is probably linked to the increasing water content and changes in short-range order, as $\mathrm{Ca}$ is substituted by $\mathrm{Mg}$ in the ACMC structure. Overall, the results reveal a high sensitivity of the ACMC phase in respect to the chemical composition (e.g. magnesium concentration) of the aqueous environment. The exchange of ions between the amorphous solid and the solution causes changes in the chemical composition of the solution (e.g. $\mathrm{pH}$ and alkalinity) and that of the solid (e.g. $\mathrm{Mg}$ content). This ion exchange probably affects the temporal stability of the amorphous precursor in solution and its subsequent transformation into distinct crystalline calcium magnesium carbonates. Essentially, our findings suggest that the $\mathrm{Mg}$ content of ACMC is not the governing parameter for its temporal stability in solution. In contrast, the chemical composition of both the solution and the amorphous solid, have to be taken into account as a potential parameter controlling ACMC stability and transformation behavior. For example, in a closed system the chemistry of the fluid (e.g. calcifying fluid in the biomineralisation space) would influence the temporal stability of the amorphous precursor and its transformation pathway to the final crystalline carbonate mineral.

\section{Conflicts of interest}

There are no conflicts to declare.

\section{Acknowledgements}

The authors are thankful to Stefanie Eichinger and Christine Pfarrmaier for their support with the analytical work. Chemical analyses were conducted at NAWI Graz Central Lab for
Water, Minerals and Rocks. This work has been financially supported by Austrian Science Fund (FWF) project number T 920-N29, and in part by DFG-FWF collaborative research initiative CHARON II (DFG Forschergruppe 1644; FWF I3028N29) and by NAWI Graz.

\section{References}

1 D. E. Jacob, A. L. Soldati, R. Wirth, J. Huth, U. Wehrmeister and W. Hofmeister, Nanostructure, Composition and Mechanisms of Bivalve Shell Growth, Geochim. Cosmochim. Acta, 2008, 72(22), 5401-5415.

2 Y. Politi, T. Arad, E. Klein, S. Weiner and L. Addadi, Sea Urchin Spine Calcite Forms via a Transient Amorphous Calcium Carbonate Phase, Science, 2004, 306, 1089-1298.

3 I. Sethmann, R. Hinrichs, G. Wörheide and A. Putnis, NanoCluster Composite Structure of Calcitic Sponge Spicules - A Case Study of Basic Characteristics of Biominerals, J. Inorg. Biochem., 2006, 100(1), 88-96.

4 J. Tao, D. Zhou, Z. Zhang, X. Xu and R. Tang, MagnesiumAspartate-Based Crystallization Switch Inspired from Shell Molt of Crustacean, Proc. Natl. Acad. Sci. U. S. A., 2009, 106(52), 22096-22101.

5 I. Khairoun, D. Magne, O. Gauthier, J. M. Bouler, E. Aguado, G. Daculsi and P. Weiss, In Vitro Characterization and in Vivo Properties of a Carbonated Apatite Bone Cement, J. Biomed. Mater. Res., 2002, 60(4), 633-642.

6 J. Aizenberg, G. Lambert, S. Weiner and L. Addadi, Factors Involved in the Formation of Amorphous and Crystalline Calcium Carbonate: A Study of an Ascidian Skeleton, J. Am. Chem. Soc., 2002, 124, 32-39.

7 S. Weiner and P. M. Dove, An Overview of Biomineralization Processes and the Problem of the Vital Effect, Rev. Mineral. Geochem., 2003, 54(1), 1-29.

8 Y. Politi, D. R. Batchelor, P. Zaslansky, B. F. Chmelka, J. C. Weaver, I. Sagi, S. Weiner and L. Addadi, Role of Magnesium Ion in the Stabilization of Biogenic Amorphous Calcium Carbonate: A Structure-Function Investigation, Chem. Mater., 2010, 22(1), 161-166.

9 K. Benzerara, N. Menguy, P. López-García, T.-H. Yoon, J. Kazmierczak, T. Tyliszczak, F. Guyot and G. E. Brown, Nanoscale Detection of Organic Signatures in Carbonate Microbialites, Proc. Natl. Acad. Sci. U. S. A., 2006, 103(25), 9440-9445.

10 E. Couradeau, K. Benzerara, E. Gerard, D. Moreira, S. Bernard, G. E. Brown and P. Lopez-Garcia, An EarlyBranching Microbialite Cyanobacterium Forms Intracellular Carbonates, Science, 2012, 336(6080), 459-462.

11 B. Jones and X. Peng, Amorphous Calcium Carbonate Associated with Biofilms in Hot Spring Deposits, Sediment. Geol., 2012, 269-270, 58-68.

12 A. Demény, P. Németh, G. Czuppon, S. Leél-Őssy, M. Szabó, K. Judik, T. Németh and J. Stieber, Formation of Amorphous Calcium Carbonate in Caves and Its Implications for Speleothem Research, Sci. Rep., 2016, 6, 39602.

13 M. Schmidt, S. Xeflide, R. Botz and S. Mann, Oxygen Isotope Fractionation during Synthesis of CaMg-Carbonate and 
Implications for Sedimentary Dolomite Formation, Geochim. Cosmochim. Acta, 2005, 69(19), 4665-4674.

14 J. D. Rodriguez-Blanco, S. Shaw and L. Benning, A Route For The Direct Crystallization Of Dolomite, Am. Mineral., 2015, 100, 1172-1181.

15 B. Purgstaller, V. Mavromatis, A. Immenhauser and $M$. Dietzel, Transformation of Mg-Bearing Amorphous Calcium Carbonate to Mg-Calcite - In Situ Monitoring, Geochim. Cosmochim. Acta, 2016, 174, 180-195.

16 P. T. Yu, C. Tsao, C. C. Wang, C. Y. Chang, C. H. Wang and J. C. C. Chan, High-Magnesium Calcite Mesocrystals: Formation in Aqueous Solution under Ambient Conditions, Angew. Chem., Int. Ed., 2017, 56(51), 16202-16206.

17 V. Mavromatis, M. Schmidt, R. Botz, L. Comas-Bru and E. H. Oelkers, Experimental Quantification of the Effect of $\mathrm{Mg}$ on Calcite-aqueous Fluid Oxygen Isotope Fractionation, Chem. Geol., 2012, 310-311, 97-105.

18 L. Brečević and A. E. Nielsen, Solubility of Amorphous Calcium Carbonate, J. Cryst. Growth, 1989, 98(3), 504-510.

19 D. Gebauer, A. Volkel and H. Colfen, Stable Prenucleation Calcium Carbonate Clusters, Science, 2008, 322(5909), 1819-1822.

20 A. V. Radha, A. Fernandez-Martinez, Y. Hu, Y.-S. Jun, G. A. Waychunas and A. Navrotsky, Energetic and Structural Studies of Amorphous Ca1-XMgxCO3nH2O $(0<\mathrm{x}<1)$, Geochim. Cosmochim. Acta, 2012, 90, 83-95.

21 C.-J. Lin, S.-Y. Yang, S.-J. Huang and J. C. C. Chan, Structural Characterization of $\mathrm{Mg}$-Stabilized Amorphous Calcium Carbonate by Mg-25 Solid-State NMR Spectroscopy, J. Phys. Chem. C, 2015, 119(13), 7225-7233.

22 C. R. Blue and P. M. Dove, Chemical Controls on the Magnesium Content of Amorphous Calcium Carbonate, Geochim. Cosmochim. Acta, 2015, 148, 23-33.

23 F. Konrad, F. Gallien, D. E. Gerard and M. Dietzel, Transformation of Amorphous Calcium Carbonate in Air, Cryst. Growth Des., 2016, 16(11), 6310-6317.

24 V. Mavromatis, A. Immenhauser, D. Buhl, B. Purgstaller, A. Baldermann and M. Dietzel, Effect of Organic Ligands on $\mathrm{Mg}$ Partitioning and $\mathrm{Mg}$ Isotope Fractionation during LowTemperature Precipitation of Calcite in the Absence of Growth Rate Effects, Geochim. Cosmochim. Acta, 2017, 207, 139-153.

25 C. R. Blue, A. Giuffre, S. Mergelsberg, N. Han, J. J. De Yoreo and P. M. Dove, Chemical and Physical Controls on the Transformation of Amorphous Calcium Carbonate into Crystalline CaCO3 Polymorphs, Geochim. Cosmochim. Acta, 2017, 196, 179-196.

26 F. Konrad, B. Purgstaller, F. Gallien, V. Mavromatis, P. Gane and M. Dietzel, Influence of Aqueous Mg Concentration on the Transformation of Amorphous Calcium Carbonate, J. Cryst. Growth, 2018, 498, 381-390.

27 B. Purgstaller, F. Konrad, M. Dietzel, A. Immenhauser and V. Mavromatis, Control of $\mathrm{Mg} 2+/ \mathrm{Ca} 2+$ Activity Ratio on the Formation of Crystalline Carbonate Minerals via an Amorphous Precursor, Cryst. Growth Des., 2017, 17(3), 1069-1078.
28 J. D. Allison, D. S. Brown and K. J. Novo-Gradac, MINTEQA2/ PRODEFA2, A Geochemical Assessment Model for Environmental Systems: Version 3.0 User's Manual, U.S. Environemtal Prot. Agency, Athens, GA, 1991, p. 107.

29 C. A. J. Appelo and D. Postma, Geochemisty, Groudwater and Pollution, Balkema, Rotterdam, NL, 1996.

30 V. Mavromatis, Q. Gautier, O. Bosc and J. Schott, Kinetics of $\mathrm{Mg}$ Partition and $\mathrm{Mg}$ Stable Isotope Fractionation during Its Incorporation in Calcite, Chem. Geol., 2013, 114, 188-203.

31 D. Tommaso and N. H. de Leeuw, Structure and Dynamics of the Hydrated Magnesium Ion and of the Solvated Magnesium Carbonates: Insights from First Principles Simulations, Phys. Chem. Chem. Phys., 2010, 12, 894-901.

32 Q. Gautier, P. Bénézeth, V. Mavromatis and J. Schott, Hydromagnesite Solubility Product and Growth Kinetics in Aqueous Solution from 25 to $75^{\circ} \mathrm{C}$, Geochim. Cosmochim. Acta, 2014, 138, 1-20.

33 S. Raz, S. Weiner and L. Addadi, Formation of HighMagnesian Calcites via an Amorphous Precursor Phase: Possible Biological Implications, Adv. Mater., 2000, 38-42.

34 E. Loste, R. M. Wilson, R. Seshadri and F. C. Meldrum, The Role of Magnesium in Stabilising Amorphous Calcium Carbonate and Controlling Calcite Morphologies, J. Cryst. Growth, 2003, 254(1-2), 206-218.

35 M. P. Schmidt, A. J. Ilott, B. L. Phillips and R. J. Reeder, Structural Changes upon Dehydration of Amorphous Calcium Carbonate, Cryst. Growth Des., 2014, 14(3), 938-951.

36 H. Nebel, M. Neumann, C. Mayer and M. Epple, On the Structure of Amorphous Calcium Carbonates A Detailed Study by Solid-State NMR Spectroscopy, Inorg. Chem., 2008, 47(17), 7874-7879.

37 J. Ihli, W. C. Wong, E. H. Noel, Y.-Y. Kim, A. N. Kulak, H. K. Christenson, M. J. Duer and F. C. Meldrum, Dehydration and Crystallization of Amorphous Calcium Carbonate in Solution and in Air, Nat. Commun., 2014, 5(7), 3169.

38 A. L. Goodwin, F. M. Michel, B. L. Phillips, D. A. Keen, M. T. Dove and R. J. Reeder, Nanoporous Structure and MediumRange Order in Synthetic Amorphous Calcium Carbonate, Chem. Mater., 2010, 22(10), 3197-3205.

39 A. C. S. Jensen, S. Imberti, S. F. Parker, E. Schneck, Y. Politi, P. Fratzl, L. Bertinetti and W. J. E. M. Habraken, Hydrogen Bonding in Amorphous Calcium Carbonate and Molecular Reorientation Induced by Dehydration, J. Phys. Chem. C, 2018, 122(6), 3591-3598.

40 D. Wang, L. M. Hamm, R. J. Bodnar and P. M. Dove, Raman Spectroscopic Characterization of the Magnesium Content in Amorphous Calcium Carbonates, J. Raman Spectrosc., 2012, 43(4), 543-548.

41 S.-Y. Yang, H.-H. Chang, C.-J. Lin, S.-J. Huang and J. C. C. Chan, Is Mg-Stabilized Amorphous Calcium Carbonate a Homogeneous Mixture of Amorphous Magnesium Carbonate and Amorphous Calcium Carbonate?, Chem. Commun., 2016, 52(52), 11527-11530.

42 V. Mavromatis, B. Purgstaller, M. Dietzel, D. Buhl, A. Immenhauser and J. Schott, Impact of Amorphous Precursor 
Phases on Magnesium Isotope Signatures of Mg-Calcite, Earth Planet. Sci. Lett., 2017, 464, 227-236.

43 E. Busenberg and L. N. Plummer, Thermodynamics of Magnesian Calcite Solid-Solutions At 25-Degrees-C and 1-Atm Total Pressure, Geochim. Cosmochim. Acta, 1989, 53(6), 1189-1208.

44 W. D. Bischoff, F. T. Mackenzie and F. C. Bishop, Stabilities of Synthetic Magnesian Calcites in Aqueous Solution: Comparison with Biogenic Materials, Geochim. Cosmochim. Acta, 1987, 51, 1413-1423.

45 W. D. Bischoff, M. A. Bertram, F. T. Mackenzie and F. C. Bishop, Diagenetic Stabilization Pathways of Magnesian Calcites, Carbonates Evaporites, 1993, 8(1), 82-89.

46 P. L. Althoff, Structural Refinements of Dolomite and a Magnesian Calcite and Implications for Dolomite Formation in the Marine Environment, Am. Mineral., 1977, 62(4), 772-783.

47 W. D. Bischoff, S. K. Sharma and F. T. Mackenzie, Carbonate Ion Disorder in Synthetic and Biogenic Magnesian Calcites: A Raman Spectral Study, Am. Mineral., 1985, 70, 581-589.

48 F. M. Michel, J. MacDonald, J. Feng, B. L. Phillips, L. Ehm, C. Tarabrella, J. B. Parise and R. J. Reeder, Structural Characteristics of Synthetic Amorphous Calcium Carbonate, Chem. Mater., 2008, 4720-4728.

49 G. M. Marion, Carbonate Mineral Solubility at Low Temperatures in the Na-K-Mg-Ca-H-Cl- $-\mathrm{SO}_{4}-\mathrm{OH}-\mathrm{HCO}_{3}-\mathrm{CO}_{3}$ $\mathrm{CO}_{2}-\mathrm{H}_{2} \mathrm{O}$ system, Geochim. Cosmochim. Acta, 2001, 65(12), 1883-1896. 